\title{
Perpaduan COBIT 4.1 dan Balanced Scorecard Untuk Menilai Tata Kelola Perguruan Tinggi
}

\section{Combination COBIT 4.1 and Balanced Scorecard for Assessing Higher Education Governance}

\author{
Elvis Pawan*1 ${ }^{1}$ Ema Utami ${ }^{2}$, Asro Nasiri ${ }^{3}$ \\ ${ }^{1,2,3}$ Universitas Amikom Jl. Ring Road Utara, Condong Catur Yogyakarta, Tlp (0274) 884201 \\ ${ }^{1,2,3}$ Magister Teknik Informatika, Universitas Amikom, Yogyakarta

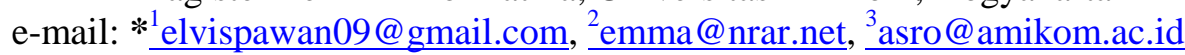

\begin{abstract}
Abstrak
Dalam perkembangan lembaga pendidikan sangat ditentukan peranan teknologi informasi(TI). Pada STIMIK Sepuluh Nopember Jayapura terdapat masalah lembaga cenderung belum menyadari pentingnya untuk orientasi terhadap layanan. Salah satu proses yang sangat penting dalam penerapan tata kelola TI dengan melakukan sebuah evaluasi yang bertujuan untuk mengetahui sejauh mana institusi dalam menerapkan tata kelola yang baik. Penelitian ini menjelaskan bagaimana sebuah lembaga pendidikan untuk meningkatkan orientasi dan layanan pada perguruan tinggi. Balanced Scorecard merupakan sebuah kerangka kerja yang baik untuk melakukan penilaian terhadap kinerja Organisasi. Perpaudan COBIT dan Balanced scorecard memberikan sebuah patokan pada costumer perspektif yang dapat dijadikan acuan manajemen pada sebuah institusi yang ingin melakukan pembenahan khususnya meningkatkan orientasi layanan. Penelitian ini memperoleh cara meningkatkan maturity level yang dapat dijadikan acuan oleh lembaga dalam menyusun tata kelola TI yang sesuai dengan best practice COBIT 4.1. Pada penelitian ini menyimpulkan bahwa tingkat kematangan tata kelola lembaga saat berada pada level 2 dengan nilai rata-rata 2,48.
\end{abstract}

Kata kunci-COBIT, Balanced Scorecard, Tingkat Kematangan

\begin{abstract}
In the development of educational institutions, the role of information technology (IT) is largely determined. At STIMIK Sepuluh Nopember Jayapura there was a problem that institutions tended to not realize the importance of service orientation. One of the most important processes in implementing IT governance is by conducting an evaluation that aims to determine the extent of institutions in implementing good governance. This study explains how an educational institution to improve orientation and service in higher education. The Balanced Scorecard is a good framework for assessing Organizational performance. The calculation of COBIT and the Balanced Scorecard provides a benchmark for the customer perspective that can be used as a reference for management in an institution that wants to make improvements specifically to improve service orientation. This study has a way to improve the maturity level that can be used as a reference by institutions in developing IT governance that is in accordance with COBIT best practices 4.1. In this study concluded that the maturity level of the governance of the institution when it is at level 2 with an average value of 2.48 .
\end{abstract}

Keywords—COBIT, Balanced Scorecard, Maturity Level 


\section{PENDAHULUAN}

Penerapan teknologi informasi akan bermanfaat jika penerapan sesui dengan tujuan visi dan misi organisasi atau institusi dengan menerapkan strategi bisnis dan strategi sistim teknologi informasi.[1] Dibutuhkan Suatu Analisa berbagai faktor yang mempengaruhi terbentuknya suatu perencanaan strategi sistem atau teknologi informasi yang adaptable dan selaras dengan strategi bisnis.[1]

STIMIK Sepuluh Nopember Jayapura merupakan sebuah Lembaga Pendidikan yang berkedudukan di kota Jayapura dimana dikeluarkan izin operasional melalui keputusan mentri Pendidikan nasional Republik Indonesia dengan nomor : 31/D/O/2006. Sesuai dengan visi dan misi institusi yang tertuang didalam rencana strategis STIMIK Sepuluh Nopember Jayapura bahwa " Menjadi Perguruan Tinggi swasta yang berdaya saing dan unggul di Provinsi Papua pada tahun 2025 dalam bidang ilmu Komputer".[2] Akan tetapi setelah terbentuknya Lembaga tersebut manajemen belum mengetahui sejauh mana progress untuk mencapai sasaran yang dimaksud, hal tersebut bukan tanpa alasan karena sampai saat ini belum pernah dilakukan sebuah evaluasi dalam bentuk pengukuran tata kelola pada sistem yang digunakan.

Penelitian ini difokuskan pada perspektif Balanced Bcorecard dan proses COBIT 4.1 sebagai berikut:Costumer perspective Balanced Scorecard dengan tujuan bisnis Improve customer orientation and service dan tujuan teknologi informasi, Ensure satisfaction of end users with service offerings and service levels proses COBIT PO8 AI4 DS1 DS2 DS7 DS8 DS10 DS13, dan make sure that Information Technology services are available as required proses COBIT DS3 DS4 DS8 DS13 selanjutnya merepresentasikan tingkat kematangan kedalam nilai maturity level. Audit Teknologi Informasi pada hakekatnya memiliki kesamaan dengan bentuk audit, operasioanal, akan tetapi kini audit teknologi informasi sudah dikenal sebagai satu satuan jenis audit tersendiri yang mempunyai tujuan lebih untuk meningkatkan tata kelola IT, sebagai suatu audit operasional terhadap manajemen sumber daya informasi yaitu efektivitas, efisiensi dan ekonomis tidaknya unit fungsional sistem informasi pada suatu perusahaan tidak terkecuali institusi Pendidikan.[3]

Beberapa penelitian yang telah melakukan audit tata kelola TI dengan menggunakan framework COBIT yang diterapkan baik pada Lembaga Pendidikan maupun perusahaan, penelitian tersebut diantaranya pada tahun 2015 Rauf Fauzan, dkk melakukan penelitian yang berjudul Audit Tata Kelola Teknologi Informasi Untuk Mengontrol Management Kualitas Menggunakan COBIT 4.1 Studi Kasus PT. Nikkatsu Electric Works, pada penelitian ini menghasilkan sebuah kesimpulan bahwa tingkat kematangan PT. Nikkatsu berada pada level 2 dan terdapat kesenjangan yang begitu jauh antara tingkat kematangan yang diharapkan, penelitian ini juga memberikan saran agar penelitian selanjutnya dapat dilakukan pada domain atau proses COBIT yang lain.[4] Pada tahun 2013 Irawan Wingdes melakukan penelitian yang diterbitkan pada jurnal Sisfotenika volume 3 nomor 2, penelitian ini berjudul Menilai Tata Kelola TI di Domain Delivery dan Support pada "MK" Dengan Menggunakan COBIT rangkuman penelitian ini menyatakan bahwa penilaian pada tata kelola TI menjadi salah satu faktor penting dalam kekesuksesan menyelenggarakan teknologi informasi pada sebuah organisasi atau perusahaan.[5] Pada tahun 2016 Robert Marco melakukan penelitian yang berjudul Indeks Penilaian Tingkat Kematangan (Maturity) IT Governace Pada Manajemen Keamanan Layanan Teknologi Informasi, penelitian ini memberikan saran agar dalam menilai manajemen keamanan tidak hanya menggunakan ISMS dengan Domain ISO 27001.[6] Pada Tahun 2014 Sakinah Farroh dkk, melaukan penelitan yang berjudul Indeks Penilaian Kematangan (Maturity) Manajemen Keamanan Layanan TI, penelitian ini memberikan kesimpulan bahwa kombinasi metodologi manajemen TI menggunakan ITIL, COBIT, dan ISO/IEC 27002 akan memberikan hasil yang lebih konferhensif dan efisien baik dari sisi persiapan maupun dari pengimplementasian.[7] 
Selanjutnya dalam penelitian ini bertujuan untuk menyelaraskan sebuah tujuan bisnis dan tujuan teknologi informasi pada sebuah organisasi menggunakan framework COBIT 4.1dan Balanced Scorecard, kedua metode ini sangat baik untuk dikombinasikan dalam menilai sebuah tata kelola TI pada sebuah perusahaan, organisasi tak terkecuali institusi Pendidikan, kelebihan dari Balanced Scorecard merupakan sebuah kerangka yang memiliki empat perspektif berbeda yang dapat mengenali dan membagi semua kondisi yang terdapat pada oraganisasi. Dengan bantuan framework COBIT maka organisasi dapat memiliki sebuah patokan dalam melakukan sebuah perubahan terhadap proses yang menjadi prioritas perbaikan.

\section{METODE PENELITIAN}

Penelitian ini menggunakan metode survey research, merupakan metode penelitian bersifat kualitatif. Penelitian Kualitatif merupakan jenis penelitian yang menghasilkan temuantemuan yang tidak diperoleh oleh alat-alat prosedur statistik atau alat-alat kuantifikasi lainnya.[8]

\subsection{Metode Pengumpulan Data}

\subsubsection{Studi Pustaka}

Metode pengumpulan data dan informasi dengan mencari data kepustakaan berupa buku, jurnal ilmiah, e-book, dan lain sebagainya yang ada kaitannya dengan penelitian.[9]

2.1.2. Kuesioner

Pengumpulan data dengan menganalisis hasil kuesioner dengan pihak yang mampu memberikan informasi terhadap permasalahan yang sedang diteliti.[9]

Dalam pemilihan responden menggunakan RACI Chart dengan kriteria pada Responsible, Accountable, Consulted, Informed (RACI Chart) COBIT 4.1. menerangkan bahwa RACI chart berfungsi untuk menunjukkan peran dan tanggung jawab suatu fungsi dalam organisasi terhadap suatu aktivitas tertentu dalam IT control objective.[10]

2.1.3. Wawancara

Dalam tahapan ini, peneliti melakukan pengumpulan data dengan cara berdiskusi atau tanya jawab kepada pihak-pihak yang terkait diantaranya Ketua STIMIK Sepuluh Nopember Jayapura, Pembantu Ketua I Bidang Akademik, Pembantu Ketua II Bidang Sumber daya Manusia dan Keuangan, Pembantu Ketua III bidang Kemahasiswaan, Kepala Laboratorium dan Staf, Kepala Unit Penjaminan Mutu, Kepala BAAK, Kepala LPPM, Hasil wawancara akan menjadi pertimbangan dalam pengolahan kuesioner serta penentuan nilai kematangan yang ada pada tiap-tiap domain atau proses yang diteliti.

2.1.4. Observasi

Metode ini merupakan cara mengumpulkan data dengan melakukan pengamatan langsung Pada STIMIK Sepuluh Nopember Jayapura terkait sistem atau kondisi yang sedang diterapkan

\subsection{Alur Penelitian}

Pada penelitian yang dilakukan terdapat beberapa langkah pokok yang dilaakukan oleh peneliti yang di representasikan dalam gambar alur penelitian pada Gambar 1. 


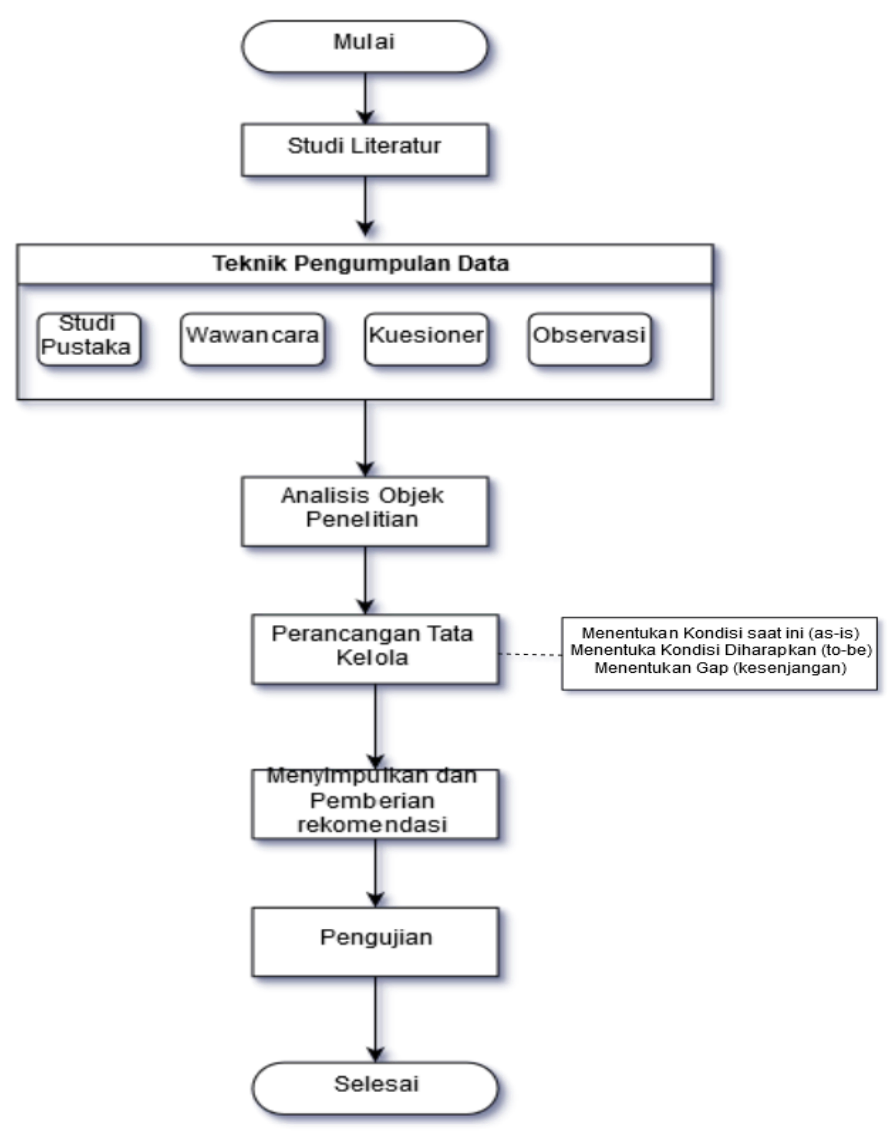

Gambar 1. Tahapan Melakukan Penelitian

\section{a. Studi Literatur}

Tahap studi literatur adalah langkah penelitian yang dilakukan dengan mempelajari data dan informasi yang bersumber dari buku,jurnal dan hasil penelitian terdahulu yang sesuai dengan topik yang dibahas pada penelitian ini.

\section{b. Pengumpulan Data Dan Informasi}

Langkah ini adalah pengumpulan data dan informasi adalah dengan melakukan studi pustaka, observasi, wawancara, dan kuesioner. Pada tahap wawancara dilakukan dengan mewawancarai pemangku kepentingan kepala BAAK, kepala Laboratorium, Ketua dan Pembantu Ketua STIMIK Sepuluh Nopember Jayapura. Pada tahap kuesioner dilakukan dengan menyebarkan kuesioner pada responden yang telah ditentukan dengan menjawab pernyataanpernyataan yang sesuai dengan COBIT

\section{c. Analisis Tingkat Kematangan Kondisi Saat Ini (as-is)}

Pada tahap ini peneliti melakukan analisis yang ada pada STIMIK Sepuluh Nopember Jayapura yang tujuannya adalah mendapatkan nilai maturity level pada sistem yang sedang berjalan

\section{d. Analisis Tingkat Kematangan Yang Diharapkan (to-be)}

Pada tahap ini peneliti melakukan analisis terhadap tingkat kematangan yang diharapkan STIMIK Sepuluh Nopember Jayapura yang tujuannya adalah mendapatkan nilai maturity level pada sistem yang akan dituju. 
e. Menentukan Nilai kesenjangan ( $g a p$ )

Pada tahap ini peneliti menentukan nilai kesenjangan antara tingkat kematangan diharapkan dengan tingkat kematangan yang sedang dijalankan

f. Pemberian Rekomendasi Perbaikan

Pada tahap ini peneliti memberikan rekomendasi perbaikan terkait hal-hal yang dapat dilakukan oleh STIMIK Sepuluh Nopember Jayapura dalam mengefisienkan biaya.

g. Penarikan Kesimpulan

Pada tahap ini peneliti menarik kesimpulan dari hasil penelitian serta memberikan saran baik kepada colon peneliti ataupun bagi pembaca yang.

\subsection{Pemetaan Antara COBIT dan Balanced Scorecard}

Pada Tahapan ini peneliti memilih atau menentukan perspektif Balanced Scorecard serta proses COBIT yang disesuaikan dengan kebutuhan Lembaga saat ini. Adapun domain serta BSC yang dipilih:

1. Domain Plan and Organize terdapat proses PO8

2. Domain Aquire and Implement terdapat proses AI4

3. Domain Delivery and Support terdapat proses DS1 DS2 DS3 DS4 DS7 DS8 DS10 DS13

\section{HASIL DAN PEMBAHASAN}

\subsection{Analisis Pengolahan Data}

Pada Tahapan ini peneliti memilih atau menentukan perspektif Balanced Scorecard serta proses COBIT yang disesuaikan dengan kebutuhan Lembaga saat ini. Adapun domain serta BSC yang dipilih dapat dilihat pada tabel 2.

Tabel 2. Hubungan BSC dan Proses COBIT

\begin{tabular}{|c|c|c|c|}
\hline $\begin{array}{c}\text { Perspektif Balanced } \\
\text { Scorecard }\end{array}$ & Business Goals & IT Goals & Proses \\
\hline \multirow[t]{2}{*}{ Costumer perspective } & \multirow{2}{*}{$\begin{array}{l}\text { Improve customer } \\
\text { orientation and service }\end{array}$} & $\begin{array}{l}\text { Ensure satisfaction of } \\
\text { end users with service } \\
\text { offerings and service } \\
\text { levels }\end{array}$ & $\begin{array}{lr}\text { PO8 } & \text { AI4 } \\
\text { DS1 } & \text { DS2 } \\
\text { DS7 } & \text { DS8 } \\
\text { DS10 } & \text { DS13 }\end{array}$ \\
\hline & & $\begin{array}{l}\text { make sure that IT } \\
\text { services are available } \\
\text { as required }\end{array}$ & $\begin{array}{l}\text { DS3 DS4 } \\
\text { DS8 DS13 }\end{array}$ \\
\hline
\end{tabular}

Pada Balanced Scorecard dipilih costumer pespektif karena pada perspektif ini menyediakan sebuah tujuan bisnis yang memfokuskan pada peningkatan orientasi layanan pelanggan dengan tujuan teknologi informasi bantuan framework COBIT 4.1 khusunya proses PO8 AI4 DS1 DS2 DS3 DS4 DS7 DS8 DS10 DS13.

\subsection{Hasil Pengukuran Maturity Level}

Berdasarkan kuesioner menggunakan COBIT 4.1 diperoleh hasil seperti yang terdapat pada tabel 3. 
Tabel 3. Hasil Pengukuran Tingkat Kematangan Tata Kelola

\begin{tabular}{ccc}
\hline No & $\begin{array}{c}\text { Proses } \\
\text { COBIT }\end{array}$ & $\begin{array}{c}\text { Nilai } \\
\text { Kematangan }\end{array}$ \\
\hline 1 & PO8 & 2.08 \\
\hline 2 & AI4 & 2.49 \\
\hline 3 & DS1 & 2.65 \\
\hline 4 & DS2 & 1.72 \\
\hline 5 & DS3 & 2.51 \\
\hline 6 & DS4 & 2.78 \\
\hline 7 & DS6 & 2.69 \\
\hline 8 & DS7 & 2.62 \\
\hline 9 & DS8 & 2.45 \\
\hline 10 & DS10 & 2.56 \\
\hline 11 & DS13 & 2.68 \\
\hline
\end{tabular}

Pada masing-masing proses didalam domain yang telah dipilih, Plan and Organize diwakili oleh PO8 berdasarkan Balanced Scorecard. Proses PO8 memiliki nilai kematangan sebesar 2.08 yakni pada level Repeatable but Intuitive pada proses AI4 memiliki nilai kematangan sebesar 2.49 dengan kategori Repeatable but Intuitive pada domain DS diwakili oleh $\mathrm{DS} 1=2.65, \mathrm{DS} 2=1.72, \mathrm{DS} 3=2.51, \mathrm{DS} 4=2.78, \mathrm{DS} 6=2.69, \mathrm{DS} 7=2.62, \mathrm{DS} 8=2.45$, DS10 $=2.56$, DS13 $=2.68$ pada level ini dibuatkan prosedur untuk pekerjaan yang sama untuk dipakai oleh berbagai pihak. Tidak terdapat pelatihan formal atau pengkomunikasian prosedur standar dan tanggung jawab diserahkan kepada masing -masing individu. Terdapat tingkat kepercayaan yang tinggi terhadap pengetahuan individu/perorangan sehingga kemungkinan terjadi error sangat besar.

Dalam penelitian dibedakan istilah antara tingkat kematangan dan nilai kematangan dimana nilai kematangan merupakan bilangan pecahan yang merepresentasikan proses pencapaian menuju suatu tingkat kematangan tertentu sesuai dengan teori COBIT. Sedangkan tingkat kematangan menunjukkan tingkat kematangan yang dicapai Lembaga dalam menjalankan sistem dan bentuknya berupa bilangan bulat.

\subsection{Tingkat Kematangan Diharapkan}

Tingkat kematangan diharapkan diperoleh dari hasil analisis terhadap hasil kuesioner dan hasil analisis tentang kondisi saat ini, selain itu tingkat kematangan merupakan permintaan dari pihak STIMIK Sepuluh Nopember Jayapura. Adapun tingkat kematangan yang akan dituju yakni pada level 3 (defined).

Untuk mendapatkan gambaran yang lebih jelas terhadap tingkat kematangan saat ini dan tingkat kematangan yang diharapkan maka peneliti menggambarkan dalam bentuk diagram rising star seperti pada Gambar 2. 


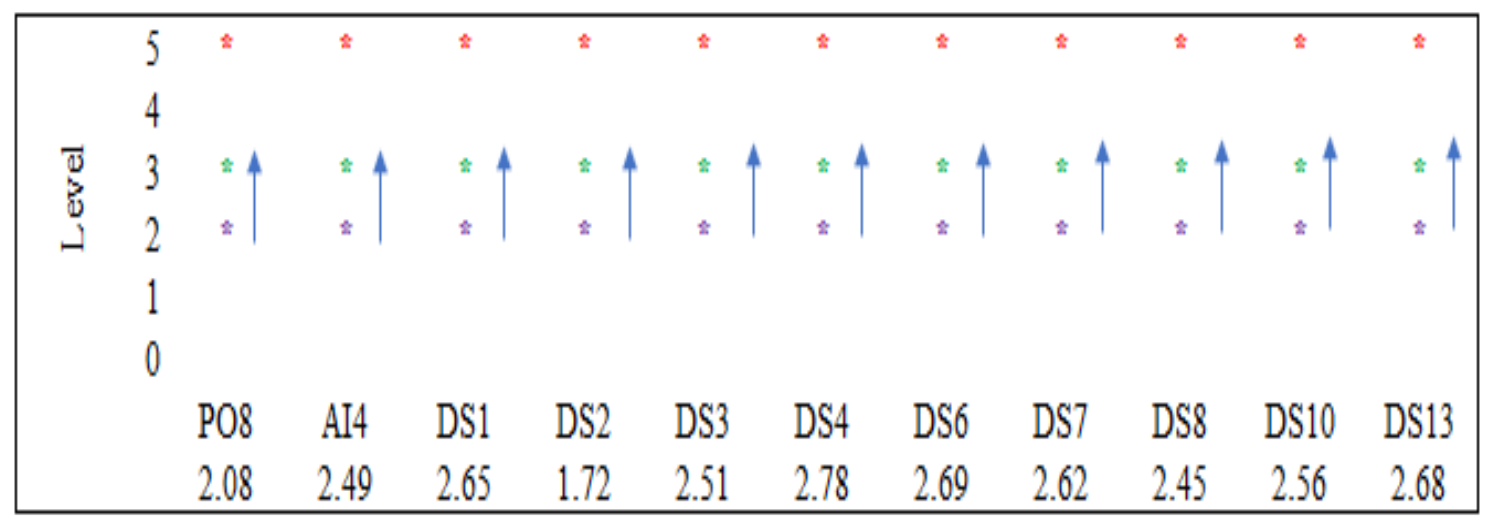

Gambar 2. Diagram Rising Star ( representasi nilai as-is dan to-be)

Gambar 2. Merupakan representasi dari nilai $a s-i s$ dan to-be dimana penelitian ini menggambarkan tujuan STIMIK Sepuluh Nopember Jayapura, pada PO8 Tingkat kematangan saat ini 2,08 akan dinaikkan pada level 3, AI4=2,49 akan dinaikkan pada level 3 DS1 $=2,65$ akan dinaikkan pada level 3, DS2 = 1,72 akan dinaikkan pada level 3, DS3=2,51 akan dinaikkan pada level 3, DS4=2,78 akan dinaikkan pada level 3, DS6=2,69 akan dinaikkan pada level 3, DS7=2,62 akan dinaikkan pada level 3, DS8=2,45 akan dinaikkan pada level 3, DS10=2,56 akan dinaikkan pada level 3, DS13=2,68 akan dinaikkan pada level 3 .

Setelah semua prose mencapai level yang sama yakni pada level 3 kemudian secara besamaan semua proses dinaikkan ke level selanjutnya yakni pada level 4 .

\subsection{Selisih Tingkat Kematangan Saat ini dan Tingkat Kematangan Diharapkan (Gap)}

Dari hasil analisis nilai kematangan saat ini dan nilai kematangan diharapkan dapat ditentukan nilai kesenjagan yang akan digunakan, sebagai acuan dalam pemberian rekomendasi perbaikan pada STIMIK Sepuluh Nopember Jayapura. Adapun nilai kesenjangan dapat dilihat pada tabel 4.

Tabel 4. Gap antara as-is dan to-be

\begin{tabular}{|c|c|c|c|c|c|}
\hline No & Proses COBIT & $\begin{array}{l}\text { Tingkat } \\
\text { Kematangan } \\
\text { saat ini }(A s- \\
\text { is) } \\
\end{array}$ & $\begin{array}{l}\text { Pembulatan } \\
\text { Tingkat } \\
\text { Kematangan (as- } \\
\text { is) }\end{array}$ & $\begin{array}{l}\text { Tingkat } \\
\text { Kematangan } \\
\text { Diharapkan (to- } \\
\text { be) }\end{array}$ & $\begin{array}{l}\text { Selisih } \\
\text { (Gap) }\end{array}$ \\
\hline 1 & PO8 & 2.08 & 2 & 3 & 1 \\
\hline 2 & AI4 & 2.49 & 2 & 3 & 1 \\
\hline 3 & DS1 & 2.65 & 2 & 3 & 1 \\
\hline 4 & DS2 & 1.72 & 2 & 3 & 1 \\
\hline 5 & DS3 & 2.51 & 2 & 3 & 1 \\
\hline 6 & DS4 & 2.78 & 2 & 3 & 1 \\
\hline 7 & DS6 & 2.69 & 2 & 3 & 1 \\
\hline 8 & DS7 & 2.62 & 2 & 3 & 1 \\
\hline 9 & DS8 & 2.45 & 2 & 3 & 1 \\
\hline 10 & DS10 & 2.56 & 2 & 3 & 1 \\
\hline 11 & DS13 & 2.68 & 2 & 3 & 1 \\
\hline
\end{tabular}




\subsection{Rekomendasi}

Memberikan usulan yang akan dijadikan acuan dalam perbaikan dalam mencapai tujuan yang sesuai dengan visi dan misi lembaga. Pemberian rekomendasi dilakukan berdasarkan hasil analisis yang telah dilakukan pada tahap sebelumnya. Rekomendasi yang diberikan berupa tindakan yang perlu dilakukan pada masing-masing proses khusnya yang menjadi objek penelitian ini.

Perlu diketahui bahwa rancangan solusi adalah bahwa proses menuju penyempurnaan adalah hal yang alamiah, secara terus menerus diupayakan sampai mencapai tujuan yang ditargetkan dalam kurun waktu tertentu, dan itu dilakukan secara bertahap.

Pada hasil penelitian ini menyatakan bahwa posisi STIMIK Sepuluh Nopember Jayapura saat ini sedang berada pada level 2 (Repeatable but Intuitive) dimana hal tersebut jika disesuaikan dengan model kematangan pada COBIT 4.1 maka pada level ini proses yang bejalan dibuatkan prosedur untuk pekerjaan yang sama untuk dipakai oleh berbagai pihak. Tidak terdapat pelatihan formal atau pengkomunikasian prosedur standar dan tanggung jawab diserahkan kepada masing -masing individu. Terdapat tingkat kepercayaan yang tinggi terhadap pengetahuan individu/perorangan sehingga kemungkinan terjadi error sangat besar. Untuk dapat mencapai Peneliti memberikan rekomendasi kepada pihak-pihak pemangku kepentingan yang secara langsung berada pada sistem dimaksud, adapun rekomendasi yang diberikan adalah sebagai berikut:

a. Rekomendasi proses PO8

1. Sistem manajemen mutu yang telah ditetapkan wajib di sosialisasikan kepada semua kalangan organisasi STIMIK Sepuluh Nopember

2. Program pelatihan Teknologi Informasi harus terus dikembangkan, misalnya Maintanance jaringan, database, design grafis dan lain-lain.

3. Peralatan Teknologi informasi yang digunakan sebagai alat praktik harus segera disiapkan

4. Mengukur kualitas Teknologi Informasi yang ada sebaiknya ada perencanaan dan dilakukan dalam kurun waktu tertentu.

b. Rekomendasi AI4

1. Kerangka kerja yang telah dibuat, petunjuk pengoperasian Teknologi Informasi.

2. Prosedur yang telah dibuat dapat dilihat oleh siapapun yang berkepentingan

3. Koreksi terhadap data-data yang telah dibuat dilakuakan secara reaktif.

4. Sistem offline dirancang untuk selalu siap digunakan jika terjadi gangguan secara online.

5. Perlu dibuatkan aturan tentang penegakan kepatuhan terhadap standar TI yang ada.

c. Rekomendasi DS1

1. Tanggung jawab setiap PIC dibagian TI harus terdefenisi dengan baik

2. Perlu dibuatkan prosedur untuk mengatasi kekurangan yang bersifat informal.

3. Layanan dibuat dan searah dengan tujuan bisnis lembaga.

d. Rekomendasi DS2

1. Prosedur yang telah terdokumentasi yang mengatur pihak ketiga tetap dipertahankan dan dievaluasi.

2. Penanggung jawab untuk pengawasan layanan pihak ketiga ditetapkan secara formal.

3. Ketentuan kontrak dengan pihak ketiga mengacu pada standar yang telah ditentukan.

4. Proses bisnis yang terkait dengan pihak ketiga rutin dievaluasi dan dilaporkan.

e. Rekomendasi DS3

1. Persyaratan atau aturan kerja di sosialisasikan kepada semua level karyawan khususnya bidang TI.

2. Sebaiknya laporan dibuat dengan menunjukkan statistik

f. Rekomendasi DS4

1. Akuntabilitas layanan manajemen tidak dilaksanakan secara searah dan berkelanjutan.

Vol. 9, No. 1, Januari 2019 
2. Perencanaan dan pengujian layanan ditetapkan dengan jelas secara berkelanjutan dan dibuat secara bertanggung jawab

3. Dilakukan pelaporan secara berkala.

4. Secara konsisten dilakukan komunikasi untuk memastikan layanan yang berkelanjutan.

g. Rekomendasi proses DS6

1. Lembaga bertanggung jawab terhadap biaya layanan informasi serta dijelaskan dan dipahami kepada berbagai pihak dan Lembaga menyediakan pelatihan formal

2. Biaya langsung maupun biaya tidak langsung dilaporkan dengan tepat waktu secara otomatis kepada pemangku kepentingan.

3. Lembaga melakukan pemantauan dan evaluasi, mengambil tindakan jika terdeteksi biaya deviasi.

4. Pelaporan biaya layanan informasi selalu dipantau oleh pemangku kepentingan.

5. Lembaga selalu meninjau agar alokasi anggaran atau biaya tetap pada batas wajar.

6. Lembaga menyediakan sistim akuntansi otomatis yang difokuskan pada layanan informasi bukan pada proses bisnis.

7. Tujuan dan metrik disetujui oleh Lembaga walaupun belum dilakukan secara konsisten.

h. Rekomendasi DS7

1. Lembaga membuat program pelatihan dan Pendidikan.

2. Mengidentifikasi dan mendokumentasikan kebutuhan palatihan

3. Disiapkan anggaran, sumber daya, fasilitas dan pelatih untuk mendukung program pelatihan.

4. Diberikan kelas formal kepada semua jajaran tentang perilaku etis dan kesadaran praktik keamanan sistem.

i. Rekomendasi DS8

1. Lembaga harus mengakui keberadaan manajemen insiden terhadap kemungkinan masalah yang terjadi didepan, misalnya kerusakan jaringan, software dan lain-lain.

2. Pelatihan dibuat tidak hanya dalam bentuk informal, akan tetapi semua distandarisasi secara formal.

3. Pelapolan insiden harus dilakukan secara formal

j. Rekomendasi DS10

1. Pemecahan masalah dan proses esklasi yang telah distandarisasi harus dilakukan secara berkelanjutan.

2. Informasi pentingnya layanan yang prima dibagikan diantara staf dan dilakukan secara aktif dan formal.

k. Rekomendasi DS13

1. Sumber daya manusia disiapkan dan dilakukan pelatihan secara formal di Lingkungan perguruan tinggi.

2. Semua pekerjaan, pelatihan yang telah selesai dilakuakan dicatatat dengan pelaporan secaera formal kepada pemangku kepentingan

\section{KESIMPULAN}

Berdasarkan hasil analisis dari penelitian yang dilakukan pada STIMIK Sepuluh Nopember Jayapura maka dapat ditarik beberapa kesimpulan:

a. Tingkat kematangan saat ini pada berada pada level 2 Repeatable but Intuitive dimana level ini proses yang bejalan dibuatkan prosedur untuk pekerjaan yang sama untuk dipakai oleh berbagai pihak. Tidak terdapat pelatihan formal atau pengkomunikasian prosedur standar dan tanggung jawab diserahkan kepada masing-masing individu. Terdapat tingkat kepercayaan yang tinggi terhadap pengetahuan individu/perorangan sehingga kemungkinan terjadi error sangat besar. 
b. Belum dilakukan alokasi anggaran TI secara konsisten, Serta pencatatan dan pengawasan dilakukan secara informal

c. Komunikasi antar departemen yang lemah, prosedur cenderung tanggung jawab diserahkan pada masing-masing individu sehingga kemungkinan kesalahan terjadi sangat besar.

d. Semua proses akuntansi belum didokumentasikan secara formal

\section{SARAN} diantaranya :

Dalam penelitian ini penulis memberikan saran pada calon peneliti selanjutnya

a. memperluas ruang lingkup penelitian pada tujuan bisnis dan tujuan teknologi informasi yang lain sehingga didapatkan tata kelola yang baik disetiap proses yang dianjurkan oleh framework COBIT 4.1

b. Agar penelitian tidak lebih bervariasi sebaiknya di kembangkan dengan mengkombinasikan antara beberapa metode

\section{DAFTAR PUSTAKA}

[1] Darmanto Y, Suyanto M , Sudarmawan 2014, Analisis Tata Kelola Teknologi Informasi Pada Lembaga Kursus dan Pelatihan,Citec Journal Vol 1 Universitas Amikom Yogyakarta, Yogyakarta.

[2] Tim Penyusun, 2016, Rencana Strategis STIMIK Sepuluh Nopember Jayapura 20162021, Jayapura

[3] Marzuki K, 2018, Audit Tata Kelola Teknologi Informasi Menggunakan Cobit 4.1 Domain Monitoring Evaluasi Pada Perguruan Tinggi Swasta, SENSITEK 2018, STIMIK Pontianak, Pontianak

[4] Fauzan Rauf, 2015, Audit Tata Kelola Teknologi Informasi Untuk Mengontrol Management Kualitas Menggunakan COBIT 4.1 Studi Kasus PT. Nikkatsu Electric Works, Jurnal Teknik Informatika dan Sistem Informasi Volume 1 No 3, Universitas Maranatha, Bandung

[5] Wingdes Irawan, 2013, Menilai Tata Kelola TI di Domain Delivery dan Support pada "MK" Dengan Menggunakan COBIT, Jurnal Sisfoteneka Vol 3. No 2, STIMIK Pontianak, Pontianak

[6] Marco Roberto, 2016, Indeks Penilaian Tingkat Kematangan (Maturity) IT Governace Pada Manajemen Keamanan Layanan Teknologi Informasi, Jurnal Ilmiah DASI Volume 17 No 2, STIMIK Amikom Yogyakarta, Yogyakarta

[7] Indeks Penilaian Kematangan (Maturity) manajemen keamanan Layanan TI, Jurnal Teknik POMITS Vol. 3 No 2, Institute Teknologi Sepuluh Nopember (ITS), Surabaya

[8] Ahmadi Rulam, 2016, Metodologi Penelitian Kualitatif, Edisi III, AR-RUZZ MEDIA, Yogyakarta

[9] Sarno R, 2009, Audit Sistem dan Teknologi Informasi, UPT Penerbitan ITS(ITS PRESS), Surabaya

[10] Murhada, Giap C Yo, 2011, Pengantar Teknologi Informasi,Mitra Wacana Media,Tangerang 